\title{
The 'postcode lottery' of the Italian Public Health bill analysed with the Hierarchy Stochastic Multiobjective Acceptability Analysis
}

Domenico De Matteis, Department of Economics, Sapienza University of Rome, Italia, domenico.dematteis@uniroma1.it

Alessio Ishizaka, Centre for Operational Research and Logistics, Portsmouth Business School, University of Portsmouth, United Kingdom, Alessio.ishizaka@port.ac.uk

Giuliano Resce, Department of Economics, Roma Tre University, Italia, giuliano.resce@uniroma3.it

\begin{abstract}
Over the last two decades, due to strong decentralization and widespread budget constraints, the Italian co-payment for health care has become a way to finance public health. This phenomenon has provoked a continuous increase of private costs of public health and an evident regional heterogeneity. As a result, a pervasive spatial inequality of access to public health care is becoming increasingly clear. The aim of this paper is to measure this inequality, mainly determined by the differences among regional copayment prices. Access, equity, and needs are all part of the phenomenon 'inequality of access', and they are difficult to define and measure in health care. For this reason, most of the previously proposed measurement methods have inherent limitations and have prompted us to use an innovative approach focused exclusively on the supply side. In particular, we focus only on the cost of health benefits (copayment). From a methodological perspective, we use a recent new version of the Stochastic Multiobjective Acceptability Analysis (SMAA), which is a methodology mainly used to build composite indicators of multidimensional phenomena out of the market. In order to deal with the hierarchical structure of the Italian health care system, we use the Hierarchy Stochastic Multiobjective Acceptability Analysis (HSMAA), which takes into account the uncertainty with respect to the weights assigned to the considered criteria, as in the standard SMAA, but also the uncertainty with respect to the weights assigned to the considered sub-criteria. Applying for the first time HSMAA to measure inequality allows us to create a unique index for each region and then to make a classification among them. The results show that, since there are different prices for the same health benefits among different regions, there are strong spatial inequalities in the cost of the Essential Levels of health care in Italy.
\end{abstract}

Keywords: Hierarchy Stochastic Multiobjective Acceptability Analysis; HSMAA; Public Health; Equity; Co-Payment; Inequality of Opportunities. 


\section{Introduction}

Equity in health is a widespread, shared goal in the most industrialized countries [66]. In recent years, given accentuated inequalities due to the economic crisis, equity in health has become one of the most pervasive priorities, even in the European Union [72]. The general aim stated by policy makers is to achieve equitable access to health care across different social groups and to reduce or not to aggravate the existing health inequalities. ${ }^{1}$ There are evidences that the most vulnerable people who most need health care do not always receive the care they deserve. ${ }^{2}$

Different population groups, such as the poor, elderly, immigrants, people with disabilities, and ethnic minorities, may have different health care needs [27]. A health care system should be designed to meet the different needs of the population in a fair, efficient, and responsive way [10, 33].

Among other concerns, the payment for health care is one of the higher concerns for groups socially and economically most vulnerable. For this reason, the health care systems with universal access to health care services do not always eliminate health inequalities. Indeed, in many countries with universal access to health care, there are still financial barriers, especially for access, and one of these is certainly the co-payment [47].

Continued growth of public health spending $[5,34,70]$ often pushes the debate about co-payment. In the context of scarce resources and growing demand for health care, its governance has to combine the adequacy of health services and equity of care, with the objective of financial stability. Among the instruments rationing the demand side, one of the preferred tools is the co-payment. Indeed, if properly applied, the co-payment can fulfil the role of protection and expansion of public health service. However, at the same time, if the co-payment is not used well, it can create or increase unequal access among users of health care [58].

In the specific case of Italy, the co-payment is managed at the regional level. This peculiarity of the Italian Health Care Service has transformed the co-payment into a tool to finance public health care. As a result, there is strong heterogeneity among the prices for the same public service in different regions, which often may lead to spatial inequality of opportunities of access to public health care. For this reason, this paper investigates the regional Italian differences in the co-payment prices in order to measure the consequent inequality of opportunities in the access of the health care system [18].

For the first time, this problem has been analysed with a Multi-Criteria Decision Making approach [24, 32]. From a methodological perspective, we use a recent new development of the Stochastic Multiobjective Acceptability Analysis (SMAA) [35, 37]. In order to take into account the hierarchical

${ }^{1}$ Fundamental policy goal within the EU, as expressed in many European policy documents (Report on health inequalities in the European Union, Brussels, September 2013)

${ }^{2}$ Among others, this has been reported in the Launch of the World Health Report 2013: Research for universal health coverage, World Health Organization, 2013, China. 
structure of the Italian co-payment system, we use the model proposed in Angilella et al. [4], hereafter Hierarchy Stochastic Multiobjective Acceptability Analysis (HSMAA). The HSMAA method allows taking into account both the uncertainty with respect to the weights assigned to the considered criteria (as in the standard SMAA) and the uncertainty with respect to the weights assigned to the considered sub-criteria. This innovative application allows us to estimate a new index of inequality of opportunities in public health in absence of information about the real health care needs of people. Our results show that, regardless of real needs, there are evidences that differences in the co-payment prices create a pervasive territorial segregation among citizens living in different Italian regions.

The rest of the paper is organized as follows. In the second section, the economic reasons for co-payment and the problem of measuring inequality of access to health services are presented. The third section describes the data. The fourth section presents the HSMAA to estimate the equity of access to health care, starting from the co-payment data. The fifth section shows the results of the inequality analysis. The sixth section contains policy implications. The last section discusses the conclusions and draws the main policy advices for the Italian case.

\section{The reasons for co-payment, the issues of health inequality, and the need for a multi-criteria approach}

\subsection{Co-payment}

As shown in the seminal work of Buchanan [9], the main problem of national health systems is that the demand is made by private or individual choices, and supply is a public or a collective choice. On the demand side, the individual pushes its demand to the point where its marginal utility is equal to the price, i.e., to zero. It follows that the demand from citizens, as patients, tends to be unlimited. On the supply side, the community decides the range and quantity of services through political representatives, taking into account cost [23]. As the government budget is limited, an unlimited demand of health services is not sustainable.

One of the most applied instruments to rationalize demand is the co-payment. The co-payment allows keeping the health service in public supply, in a sustainable way and at a lower price than the free market supply. Indeed, empirical evidences have shown that the co-payment restricts the phenomena of the moral hazard [52], which leads to over-consumption of health goods and services in the presence of the comprehensive insurance coverage [47]. However, the co-payment can be a protection and an expansion of the National Health Service, only if it does not constitute a financial barrier to access of health care services for low-income groups [31].

\subsection{The Italian co-payment system}

In Italy, Law no. 537 introduced a comprehensive framework of co-payment in 1993. The first health copayment in Italy involved specialist visits and pharmaceutical assistance (prescribed drug services). After almost a decade, however, the Finance Act for 2001 abolished the national co-payment. This resulted in a big increase in national health expenditure, which forced the government to reintroduce 
the co-payment by Law no. 405/2001, starting from 2002. Different from the previous co-payment framework (1993-2001), the co-payment introduced in 2002 was a national tool of regional public spending restraint.

Law no. 405/2001 was a turning point in the use of the co-payment, because since 2002, the regional copayment has been used mainly for covering regional health deficits and no longer limiting overconsumption of health care services. The latter law, in fact, explicitly states that the regions cover any management deficits are covered with cost-sharing health spending, including the co-payment. The copayment then becomes a tool for making money and contributing to covering the budget deficits of the regions [58].

The Finance Act of 2007 introduced an additional co-payment to the previous specialist visits and a new co-payment for emergency services. The first was the 'super-ticket', a new private cost only for accessing public health facilities for specialized services, and the second was a new co-payment for emergency services (white codes). ${ }^{3}$ The 'super-ticket' has been applied since 2011 (D.M. no. 98/2011).

As a result, there are now three main types of co-payments in Italy: for emergency services, for specialist visits, and for prescribed drugs. In the application of co-payments, regions have acted differently. These differences, together with the above-mentioned continuous increase of co-payments, provoked a strong regional heterogeneity in the private cost of public health. This widespread diversity creates cost differences for the same service among different regions [48]. There are evidences that this process increases the horizontal income-related inequities in health care [21, 22]. This heterogeneity clearly creates a pervasive spatial inequality of access to public health care.

\subsection{Health inequality definitions}

According to the work of Roemer [55], inequalities in outcomes are the result of two sources: inequalities due to factors for which people can be held responsible and inequalities due to circumstances beyond individual control. The first source may be considered acceptable; the second, however, is unfair. Health care is certainly one of the sectors in which individual outcome is strongly related to factors beyond individual control.

There is a large consensus about the relevance of equity in the health sector, but there is little agreement on how to measure equity or even how to define what the term means. One of the main reasons for increasing attention on this issue is that health inequality systematically increases the segregation of people who are already socially disadvantaged.

As far as the definition is concerned, Braveman and Gruskin [7] define equity in health as the absence of disparities, both in health and in its key social determinants, which are associated with social advantage/disadvantage. According to Waters [67], an appropriate indicator for estimating equity of the health system is access to services. This is the reason why many studies have focused on the equity

${ }^{3}$ Not in the case of urgent cases, where the patient is in critical condition. 
of access to health care and the consequent inequality $[15,16,20]$. Access can be defined as the use of health services conditional to the need for care [67], but while the use of health services can be observed, information about personal need is difficult to be extracted.

\subsection{Measuring access}

According to the works of Allin and Mossialos [1] and Lindeboom and Van Doorslaer [40], equity of access to health care has been measured in three different ways: equal health outcomes, same utilization of health care services for equal needs, and equal access to health care for equal needs.

In many works, utilization of health care services is considered a good proxy to measure access to health care $[6,44]$. This approach leads to estimating the production of the health care sector, and the consequent inequality in the outcomes is taken as proxy of inequality of access. However, utilization of health care is influenced by needs, and needs differ between people. Different population groups, such as the poor, seniors, immigrants, the disabled, and ethnic minorities may have different health care needs [27]. Consequently, if people in different socioeconomic groups report the same health care use, this does not mean that access is equitable. On the contrary, this situation may even be unfair, since poor people often need more health care. Therefore, measuring the outcome is not enough to understand the equity in access to health care. It is necessary to take into account needs of health care services [54].

There is no consensus on the definition of needs for health care, but there is a crucial component to the needs, which is the individual state of health [46]. The main issue in measuring the state of health is data collection. The surveys on health needs are generally based on self-assessments; therefore, they are subjective, prone to bias of formulation of the questions and to psychosocial and cultural factors.

Even when the needs are well defined, comparing needs and utilization leads to the intrinsic problem of measuring utilization. Indeed, as in all economic sectors, utilization of health care is influenced by both the supply and demand of services. The main problem, in this case, is that demand for health services is affected by many exogenous factors, such as: different individuals' perceptions, different information among individuals, and different risk aversions; above all, cultural and religious aspects affect the demand for health care [50]. In other words, since some people may refuse treatment for various reasons (religious, cultural, different preferences), utilization cannot be used when equity of access is evaluated. Equity of access to health care can, therefore, only be defined and measured as equal access for equal needs [26, 67].

The term access is defined in Mooney [43] as an opportunity and, more specifically, 'the use of this opportunity'. Some authors [69] have defined this as the ability to guarantee a series of health care services at a certain quality-level subject to a specified maximum level of personal inconvenience and cost while in possession of a specified level of information. Le Grand [39] defines access as costs incurred in receiving health care services. The cost must be interpreted in terms of money and time that individuals may incur using services. Measuring the cost that individuals may incur using services means that there is uncertainty about the real needs and, consequently, the real use of the service. In 
other words, in the inequality of opportunities definition, it is fundamental to consider the 'veil of ignorance', as proposed by Rawls [53] about health needs.

\subsection{Measuring inequality}

Waters [67] proposes two indicators to measure equity in the distribution of access to health care: (1) a modified version of the Gini coefficient, also called a concentration coefficient, and (2) the Atkinson distributional measure. These two indicators have been used in three main works $[45,49,62]$.

Morris et al. [45] investigate the inequality in use of GPs, outpatient visits, day cases, and inpatient stays in England. From a data perspective, they use a linked data set, which combines information on health status and socio-economic circumstances of individuals, with information on local supply conditions. They find that utilization of care is linked to income, ethnicity, economic status and education. On average, low-income individuals and ethnic minorities tend to have lower use of secondary care and higher use of primary care. Wagstaff and Van Doorslaer [62] estimate concentration indices and progressivity indices, based on the Kakwani [29] methodology at country level in Europe. Regarding direct taxes, they find that Italy is the country with the lowest degree of progressivity. Regarding indirect taxes, instead, Italy is one of the few progressive countries. As expected, Wagstaff and Van Doorslaer [62] find that out-of-pocket payments tend to be highly regressive in general. O'Donnell et al. [49] provide a systematic practical guide to the measurement of a variety of aspects of health equity. One of the most important chapters is dedicated to the concentration index.

In general, the focus of previous works is one partial inequality indicator, which is eventually used to measure the influence of certain individual characteristics (income, socioeconomic status, race, gender) on some variables of outcomes [63, 64,65]. Concentration curves and concentration indices have been the workhorses for large and rapidly growing empirical literature on socioeconomic inequalities in health care [20]. Such a partial approach has been driven by the technical fact that concentration curves and concentration indices are defined in single-dimensioned cases. However, as explained by Giannoni and Franzini [21], access is a multidimensional concept. Among others, Klomp and De Haan [30] suggest that multidimensionality is intrinsic in the definition of health provided in the Constitution of the World Health Organization [71]. Therefore, we propose dealing with inequality in health by means of a Multi-Criteria Decision Analysis approach. By linking the concepts of cost from Le Grand [39], opportunity from Mooney [43], and uncertainness from Rawls [53], we propose measuring the inequality of opportunities by evaluating only the barriers to accessing public health care services. Regardless of the unknown real needs and use, we assume that inequality of access to public health care is related to cost. Therefore, in our model, the index of inequality of opportunities is given by the sum (weighted by the uncertainty) of co-payment prices. From a methodological standpoint, we use the idea of Greco et al. [25], where the SMAA approach is used to take into account a large sample of randomly extracted vectors of weight to rank regions. Italy is well suited for this measurement, as the level of cost (co-payments) varies from region to region. 


\section{The data}

Our analysis is conducted using secondary data collected from four different sources: official website of the regions, the National Agency for Health Care Services (AGENAS), the National Federation of Pharmacists (FEDERFARMA), and the online newspaper for the Italian health care sector (quotidianosanità). These surveys report the value of existing co-payment prices in Italian regions in various forms. In this paper, we use this data to estimate the territorial inequality of opportunities to access public health in all 21 Italian regions.

Table 1 indicates the minimum and maximum prices for each co-payment type. The dispersion is quite large, as also indicated by the standard deviation. This is the first evidence of heterogeneity in prices paid by citizens for the same public health care service in different regions.

Table 1. Descriptive statistics

\begin{tabular}{lrrrr}
\hline Service & Min. & Max. & Average & S. Dev. \\
\hline Emergency & 8 & 50 & 26.57 & 8.62 \\
Specialist visits & 36.15 & 66.15 & 48.26 & 7.85 \\
Prescribed drugs* & 0 & 8.5 & 3.08 & 2.12 \\
\hline
\end{tabular}

Sources: agenas.it, federfarma.it. Notes: Update to 2015; values in euros; ${ }^{*}$ one prescription and one pack of drugs

Regarding prescribed drugs and emergency services, the regions applied co-payment with highly differentiated frameworks.

By analysing the specific cases, the co-payment of emergency emerges as quite homogeneous: almost all regions apply 25 euros for the 'white codes'. ${ }^{4}$ The higher level of emergency co-payment is in Campania and Bozen, with 50-euro cost sharing, while the lower level is in Friuli Venezia Giulia. ${ }^{5}$ Regarding the specialist services, the situation is more heterogeneous, mainly because of the 'super ticket' effect. Nine regions apply the national legislation (Friuli Venezia Giulia, Liguria, Molise, Apulia, Marche, Lazio, Campania, Calabria, and Sicily). Five regions have modulated cost sharing based on the income of citizens (Emilia-Romagna, Abruzzi, Veneto, Tuscany, and Umbria). Two regions have modulated the co-payment based on the cost of health care service (Lombardy and Piedmont). Five regions do not apply the 'super-ticket' (Aosta Valley, Sardinia, Bozen, Basilicata, and Trento apply only three euros for super-ticket). The lower level of co-payment for specialist services is in Aosta Valley, Abruzzi, Basilicata, and Bozen, with 36.15 euros per visit. Lombardy and Piedmont ${ }^{6}$ have the highest prices, because in these regions, co-payment prices are based on the service price. In those regions, copayment can reach 66.15 euros. In the prescribed drug cost sharing, Sardinia, Marche, and Friuli V.G. do not apply any co-payment, while in Apulia, it can reach 8.5 euros for one pack of drugs. High cost sharing for prescribed drugs can also be found in Lombardy, Piedmont, Veneto, and Tuscany. It is worth

\footnotetext{
${ }^{4}$ Some regions (Calabria, Bozen, and Sardinia) apply co-payment also to 'justified cases' called green codes, but we did not consider this.

${ }^{5}$ In Friuli V.G., there is a tariff for other specialist services in emergency.

${ }^{6}$ For Lombardy and Piedmont, we considered all the possible cost sharing based on the price of services.
} 
mentioning that Emilia-Romagna, Tuscany, Abruzzi, Veneto, and Umbria modulate the specialist visits and the prescribed drug co-payment based on income. For these regions, in our estimates, we use the median regional income from ISTAT [28] in order to estimate the private cost and consequent inequality.

\section{Methodology}

In the Multi-Criteria Decision Analysis (MCDA) problem [24, 32], there is a set of alternatives:

$$
\text { (1) } \quad A=\left\{a_{1}, \ldots, a_{m}\right\}
$$

is evaluated on a set of criteria:

$$
\text { (2) } \quad G=\left\{g_{1}, \ldots, g_{n}\right\}
$$

In this study, we assume that the inequality of access is related to user cost of public health care. Thus, our alternatives are the 21 Italian regions, and the criteria are the three categories, with respect to which those regions choose the three service co-payment prices: price of emergency service, price of specialist services, and price of prescribed drug service.

Since we consider the inequality of access equal to the user cost of public health care, the index can be seen as the sum of the co-payment prices of the services used. In this case, the value function that aggregates the user costs is given by the number of times the citizen uses each of the three services, multiplied by the relative co-payment price. For each region, $a_{k} \in A$, we can estimate the following inequality of access:

$$
u\left(a_{k}, w\right)=\sum_{i=1}^{n} w_{i} g_{i}\left(a_{k}\right)
$$

where $w_{i}$ is the number of times a citizen uses the service $i$. The problem is that the demand is unknown. Therefore, we do not know how many times a citizen will use each service $i$.

If we assume that each citizen uses health care services the same number of times, our inequality of access index can be obtained by the simple arithmetic mean where, in (3), we have $w_{1}=w_{2}=w_{3}=w_{i}$. However, in this case, we assume that each citizen has exactly the same number and same kind of health problems, and we believe in an abstract and unrealistic 'representative agent' consuming health care.

Our research question is: How does the inequality of access ranking of the regions change when the number of times a citizen needs each service is different for each person? In other words, we want to know what happens to the ranking when there is uncertainty about health needs as proposed in the 'veil of ignorance' concept introduced by Rawls [53].

In the MCDA literature, this question is addressed with the Stochastic Multiobjective Acceptability Analysis. Introduced by the seminal work of Lahdelma et al. [35], SMAA is a method able to take into account the uncertainty with respect to the weights assigned to the considered criteria. After the original SMAA, which estimates acceptability index for each alternative measuring volume of weights that give each alternative the best ranking position, several modifications to the basic model are proposed in the literature. Lahdelma and Salminen [37] introduce SMAA-2, which extends SMAA by considering all 
ranks. Lahdelma et al. [36] develop SMAA-O, which is a method dealing with problems with ordinal criteria information. Lahdelma and Salminen [38] propose the combination of SMAA-2 and Data Envelopment Analysis [11]. Tervonen and Lahdelma [59] present methods for computations through Monte Carlo simulation. Corrente et al. [12] combine SMAA with PROMETHEE methods in order to explore the parameters compatible with preference information of the decision maker. Angilella et al. $[3,4]$ combine the Choquet integral with SMAA and obtain robust recommendations and robust ordinal regression.

In order to take into account the uncertainty with respect to the weights assigned to the considered criteria and to the imprecision of the evaluation completed on considered criteria, SMAA-2 considers two probability distributions, $f_{W}(w)$ and $f_{\chi}(\xi)$ on $W$ and $\chi$, respectively, where:

$$
W=\left\{\left(w_{1}, \ldots, w_{n}\right) \in R_{+}^{n}, w_{1}+\ldots+w_{n}=1\right\}
$$

and $\chi$ is the evaluation space, i.e., the space of the value that can be taken by the criteria (co-payment prices) $g_{i} \in G$.

SMAA-2 introduces a ranking function relative to the alternative $a_{k}$ :

$$
\operatorname{rank}(k, \xi, w)=1+\sum_{h \neq k} \rho\left(u\left(\xi_{h}, w\right)>u\left(\xi_{k}, w\right)\right)
$$

where $\rho($ true $)=1$, and $\rho($ false $)=0$.

Then, for each alternative $a_{k}$, for each value that can be taken by criteria $\xi \in \chi$, and for each rank $r=$ $1, \ldots, l$, SMAA-2 computes the set of weights of criteria for which alternative $a_{k}$ assumes rank $r$ :

$$
W_{k}^{r}(\xi)=\{w \in W: \operatorname{rank}(k, \xi, w)=r\}
$$

The SMAA-2 evaluation is based on the computation of the rank acceptability index, which is the relative measure of the set of weight vectors and evaluations on considered criteria for which the region $a_{k}$ gets rank $r$ :

$$
b_{k}^{r}=\int_{\xi \in \chi} f_{\chi}(\xi) \int_{w \in W_{k}^{r}(\xi)} f_{W}(w) d w d \xi
$$

where $b_{k}^{r}$ is the probability that alternative $a_{k}$ has the $r$-th position in the preference ranking.

As explained in Section 3, some Italian regions modulate the co-payment price on the basis of services price. It follows that sometimes there is a differentiation among typology prices of the same service (criterion) in the same region (alternative). In other words, in some regions, we have differentiations within the criteria, and therefore sub-criteria are introduced. A graphical representation of an example of our problem is given in Figure 1. The structure of the problem is hierarchical, because, depending on the region, services are sub-divided by different typologies with different associated costs. Since this problem cannot be solved with the standard SMAA, a Hierarchy SMAA has been developed for solving this particular problem. 


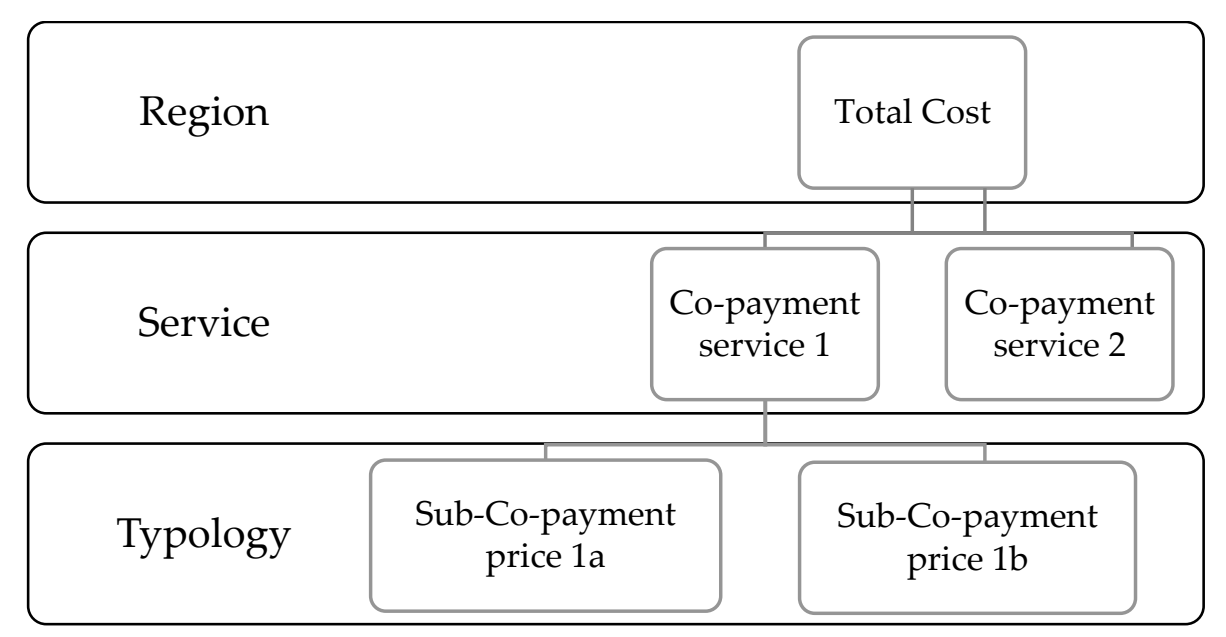

Figure 1. Problem structure

In the MCDA literature, Saaty [56] first proposed the hierarchical structure of decision problems in the Analytic Hierarchy Process (AHP). Thereafter, it appeared also in the Multi-Criteria Hierarchy Process (MCHP) of Corrente et al. [14]. Angilella et al. [4] proposed the inclusion of hierarchical structure to SMAA, and it extended to ELECTRE III in Corrente et al. [13]. In what follows, we present the implementation of the Hierarchy SMAA proposed in Angilella et al. [4] for our health care study.

In our problem, each criterion (co-payment price) $g_{i} \in G$ is given by the weighted sum of sub-criteria $q_{i j} \in Q_{i}$ :

$$
g_{i}=\sum_{j=1}^{s} v_{i j} q_{i j}
$$

In this case, the inequality of access estimated as the user cost of public health care becomes the sum of co-payment prices, which are the sum of sub-co-payment prices. The new value function to aggregate the evaluations of a region, from $A$ with respect to the $g_{i}$ co-payments from $G$, with respect to the typology from $Q_{i}$, is a double weighted sum. For each region $a_{k} \in A$, we can estimate the following inequality of access evaluation:

$$
u\left(a_{k}, w, v_{k}\right)=\sum_{i=1}^{n} w_{i} \sum_{j=1}^{s} v_{i j} q_{i j}\left(a_{k}\right)
$$

where $w_{i}$ is the number of times a citizen uses the service $i$, and $v_{i j}$ is the number of times a citizen uses the specific typology $j$.

In order to consider the hierarchy of this problem, we use HSMAA. This approach allows us to take into account: (1) the uncertainty with respect to the weights assigned to the criteria (as in the standard SMAA) and (2) the uncertainty with respect to the weights assigned to the sub-criteria.

The HSMAA considers three probability distributions: $f_{W}(w), f_{V}(v) ; f_{\chi}(\xi)$ on $W, V$; and $\chi$, respectively, where: 


$$
\begin{aligned}
& \boldsymbol{W}=\left\{\left(\boldsymbol{w}_{1}, \ldots, \boldsymbol{w}_{\boldsymbol{n}}\right) \in \boldsymbol{R}_{+}^{\boldsymbol{n}}, \boldsymbol{w}_{\mathbf{1}}+\ldots+\boldsymbol{w}_{\boldsymbol{n}}=\mathbf{1}\right\} \\
& V=\left\{\left(v_{i 1}, \ldots, v_{i s}\right) \in R_{+}^{s}, v_{i 1}+\ldots+v_{i s}=1, i=1, \ldots n\right\}
\end{aligned}
$$

and $\chi$ is the space of the value that can be taken by the sub-criteria $q_{i j} \in Q_{i}(i=1, \ldots, n)$.

We introduce a ranking function relative to the alternative $a_{k}$ :

$$
\operatorname{rank}(k, \xi, w, v)=1+\sum_{h \neq k} \rho\left(u\left(\xi_{h}, w, v_{h}\right)>u\left(\xi_{k}, w, v_{k}\right)\right)
$$

where $\rho($ true $)=1$, and $\rho($ false $)=0$.

Then, for each alternative $a_{k}$, for each evaluation of alternatives $\xi \in \chi$, and for each $\operatorname{rank} r=1, \ldots, l$, HSMAA computes the set of weights of criteria for which alternative $a_{k}$ assumes rank $r$ :

$$
W_{k}^{r}(\xi, v)=\{w \in W: \operatorname{rank}(k, \xi, w, v)=r\}
$$

HSMAA evaluation is based on the computation of the rank acceptability index, which is the relative measure of the set of weight vectors and evaluations on considered criteria for which the region $a_{k}$ gets rank $r$ :

$$
b_{k}^{r}=\int_{w \in W_{k}^{r}(\xi)} f W(w) \int_{\xi \in \chi} f \chi(\xi) \int_{v \in V} f V(v) d v d \xi d w
$$

$b_{k}^{r}$ is the probability that alternative $a_{k}$ gets the $r$-th position in the preference ranking.

As Angilella et al. [4] suggest, the rank acceptability indices in (13) can be used to estimate the upward and downward cumulative acceptability indices proposed by Angilella et al. [2]. Formally, the downward cumulative rank acceptability index for the rank $l$ is given by:

(14) $b_{k}^{\leq l}=\sum_{s=1}^{l} b_{k}^{s}$

In words, $b_{k}^{\leq l}$ is the frequency that the region $a_{k}$ gets a position not greater than $l$. With the same rationale, the upward cumulative acceptability index for the rank $l$ can be estimated as:

(15) $\boldsymbol{b}_{\boldsymbol{k}}^{\geq l}=\sum_{s=l}^{m} \boldsymbol{b}_{k}^{s}$

where $b_{k}^{\geq l}$ is the frequency that the region $a_{k}$ gets a position greater than $l$.

From a computational perspective, the multidimensional integrals defining the considered index are estimated by using Monte Carlo simulations.

In our application, in absence of information about the demand, we consider uniform probability distributions $f W(w)$ on $W$ and $f V(v)$ on $V$, while we do not consider the probability distribution $f \chi(\xi)$, because we know the value of the considered criteria. To rank the Italian regions (spatial alternatives), we apply the HSMAA technique to 360,000 extractions of $w$ and $v$ vectors.

\section{Results}

As we have 360,000 extractions and therefore 360,000 rankings, a descriptive statistic gives a general understanding. The higher and lower rank (obtained at least on one ranking) and the mode and median 
rank are given in Table 2. Our ranks are in terms of expensiveness of the public health bill. Therefore, the higher the rank of the region, the higher the final bill will be for public health users, and the higher inequality of access will be. From Table 2, it is clear that Campania is by far the worst place for health costs. Indeed, Campania is the only region with its mode and median on the first rank. This means that, by taking a uniform distribution of health needs, more than 50 per cent of the time ( 97 per cent, see Table in the appendices), Campania has the most expensive public health bill. The Bozen, Calabria, Piedmont, and Lombardy indexes follow the Campania disaster, with certain distance. Indeed, these four regions can achieve the first rank, and they have the mode and median above the fourth rank. In practice, it means that, with more than 50 per cent of cases, living in those regions results in at least the fourth most expensive public health bill.

On the top of the ranking, Friuli Venezia Giulia has the least expensive public health bill. Then, at some distance, Aosta Valley, Abruzzi, and Molise also prove to be cheap in public health care services.

Bozen and Abruzzi are two interesting cases, because their cost systems can be either the worst or the best, depending on the probability of getting a specific health problem. In the Bozen case, this phenomenon can be explained by its highest emergency co-payment and its lower specialist co-payment price. In the case of Abruzzi, the results are related to the fact that its prices are always close to the average price.

\begin{tabular}{lcccc} 
Table 2. Descriptive statistic of the ranking of Inequality of & Access in Public Health Care \\
\hline Regions & Higher & Mode & Median & Lower \\
\hline Piedmont & 1 & 3 & 4 & 17 \\
Aosta Valley & 9 & 18 & 18 & 19 \\
Lombardy & 1 & 3 & 4 & 18 \\
Bozen & 1 & 2 & 3 & 21 \\
Trento & 16 & 17 & 17 & 20 \\
Friuli Venezia Giulia & 12 & 21 & 21 & 21 \\
Veneto & 1 & 6 & 6 & 9 \\
Liguria & 1 & 6 & 6 & 9 \\
Emilia-Romagna & 9 & 14 & 14 & 15 \\
Tuscany & 1 & 13 & 14 & 14 \\
Umbria & 9 & 14 & 14 & 15 \\
Marche & 8 & 12 & 13 & 20 \\
Lazio & 4 & 5 & 6 & 17 \\
Abruzzi & 1 & 20 & 18 & 21 \\
Molise & 8 & 11 & 12 & 18 \\
Campania & 1 & 1 & 1 & 8 \\
Apulia & 1 & 10 & 8 & 14 \\
Basilicata & 14 & 19 & 19 & 20 \\
Calabria & 1 & 3 & 3 & 11 \\
Sardinia & 6 & 12 & 11 & 19 \\
Sicily & 5 & 9 & 8 & 14 \\
\hline
\end{tabular}


In figure 2, we present a graphical representation of the Ranking Acceptability index of Inequality of access in health care. The regions are ranked according to the median acceptability index. It is interesting to note that two of the three most accessible regions (Friuli Venezia Giulia and Aosta Valley) are Northern regions, while two of the three least accessible (Campania and Calabria) are Southern regions. However, Italy has a long history of persistent dualism, North-South, in which the North outperforms the South in economic performances and well-being, a phenomenon well known as 'questione meridionale' $[25,42,57,61]$; our results show that this dualism does not involve the public health expenditure. 


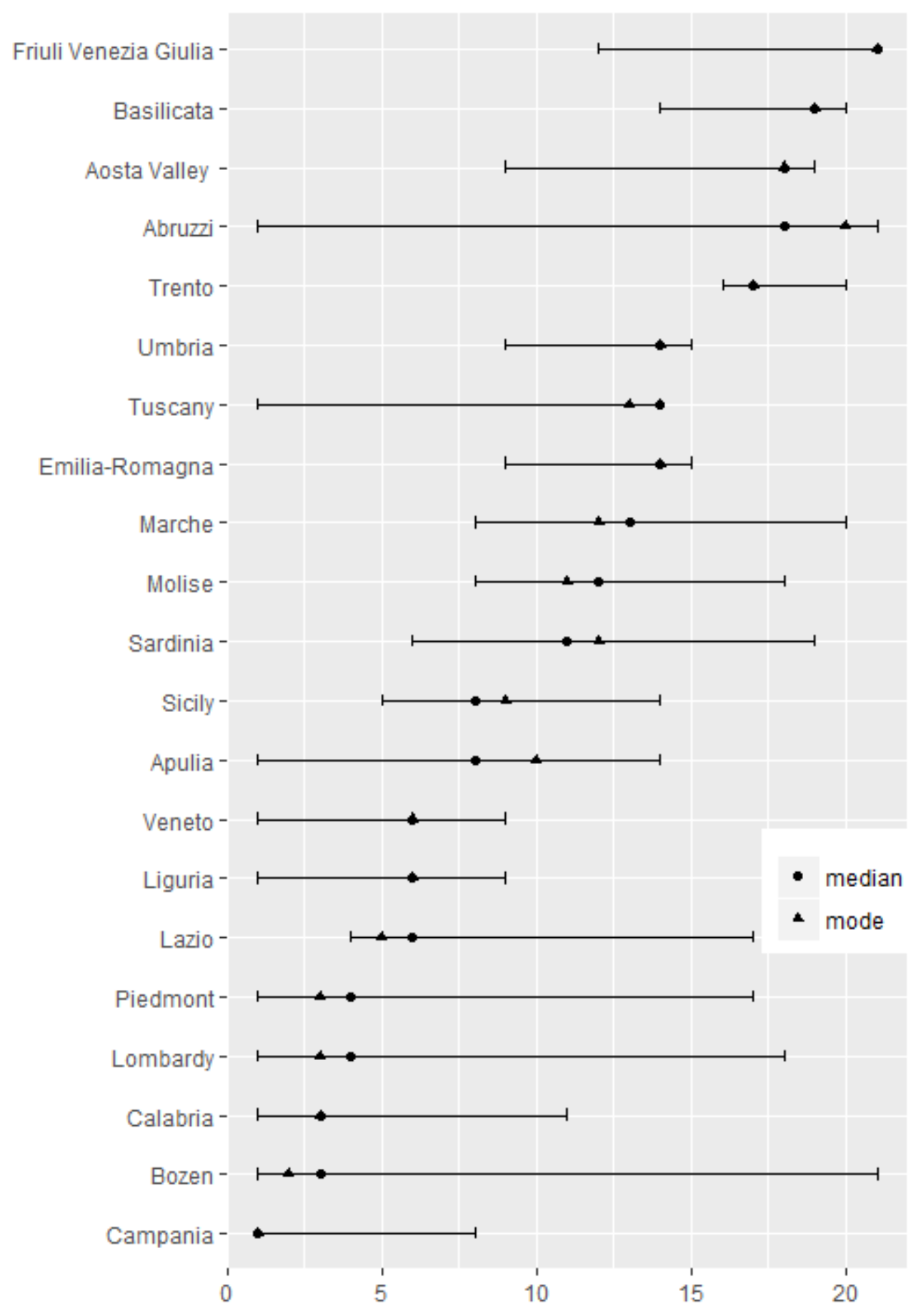

Figure 2. Rank acceptability indices by median

Figure 3 shows a map of the regional probability in the three highest (left part of Figure 3 ) and in the three lowest (right part of Figure 3) rank positions, according to the sum of the bills of public health expenditure. Technically, in Figure 3, we report the downward (14) and upward (15) rank acceptability indices $[2,4]$ for the $3^{\text {rd }}$ and $18^{\text {th }}$ rank, respectively. 
Looking at the left side, it emerges that the higher probabilities are in the big Northern and Southern regions, while the central regions and the Islands have less probability of being the top three most expensive regions. The North-South divide, which is striking in the ranking based on per capita GDP, is not present in terms of public health expenditure. In addition, it emerges that the smallest regions (in particular Aosta Valley, Friuli Venezia Giulia, Molise, and Basilicata) are better for keeping the price of public health low compared with the biggest regions (Campania, Lombardy, and Piedmont). Considering that Patrizii and Resce [51] found that the smallest regions outperform the big ones in terms of efficiency of health care in Italy, the low cost of public health care services in the smallest regions may be due to their lower costs of production.
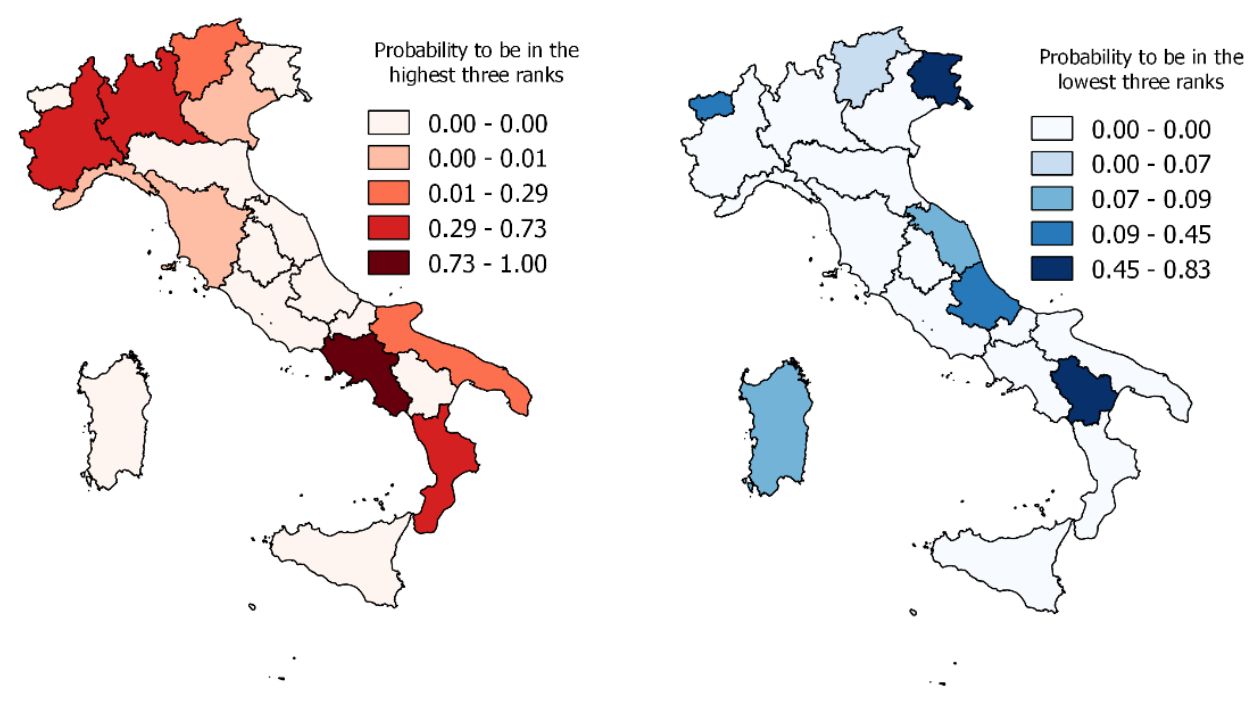

Figure 3. Probability of being in the Highest (left) and Lowest (right) three rank positions ${ }^{7}$

To summarize, the results make clear that, since there are different prices for the same public health benefits among different regions, there are strong spatial inequalities in the cost of the Essential Levels of health care in Italy. Regardless of real needs of health care, differences in the co-payment prices create a pervasive territorial segregation among citizens living in different Italian regions. This is a paradox in a country with a National Public Health System [17].

\section{Policy implications}

From a policy perspective, our results suggest taking into account the regional disparities when decisions are made in public health care decentralization. Moreover, our results clearly show the damages provoked when the co-payment becomes a tool to finance public health as an alternative to

\footnotetext{
7 The Trentino Alto Adige values are estimated based on the Trento and Bozen average.
} 
general contributions. National Health Service (NHS) is a system of the welfare state, which aims for the same standard health care of the citizens of a country, wherever they live. In Italy, profound interregional differences in health care expenditure may aggravate the already-existing inequalities among regions [21,48]. The main problem is that, since 2002, regional co-payment revenues are used to finance spending. This is proven by the fact that regions with financial stability plans have higher copayment prices (see Piedmont, Lazio, Campania, and Calabria for specialist visits). One of the most controversial parts of the Italian co-payment is definitely the 'super-ticket', introduced in 2007 - the tariff that serves as a ticket to the NHS. The 'super-ticket' has the stated objective of improving the economic and financial equilibrium of the regions, but it creates three serious health problems: (1) the outflow of some benefits from the public system; (2) the renunciation of expensive care for a part of the population; and (3) a paradoxical decline in public revenue. Referring to the last point, the 'super ticket'

raises the cost of some performances beyond their value, creating distorting effects on consumer choices for which it might be cheaper to pay the full price of the private market.

From a distributional perspective, the worst situation lies in regions where co-payment prices are modulated according to the service value. In these cases, market mechanisms are introduced in a sector where market failure is the reason for justifying public intervention. One of the major consequences is that a part of the population renounces more expansive health care, endangering the universality of health care.

The reason for the co-payment is to empower users regarding the cost of healthcare. The Italian system fails in this objective. In addition, the tariffs applied in some regions are likely to violate the universality principle of the National Health Service laid down in Article 32 of the Italian Constitution, accentuating the risk of serious inequalities in accessing the essential levels of assistance.

To restore a coherent sharing scheme in Italy, the ticket should return to its original role in reducing over-consumption. It is therefore necessary to remove from the regions the perverse incentive to use copayment as an alternative to taxes: a solution might be to disconnect co-payment revenue from financing health expenditure.

\section{Conclusions}

This paper analyses the regional differences in the application of the co-payment in the Italian National Health Care Service. In particular, it measures the inequality of opportunities in accessing public health care among the regions, due to the difference in co-payment prices.

Following the previous literature focused on inequality of opportunities in health care service, we propose measuring the inequality of access to public health care through the cost of services, regardless of unknown health needs and use. In our study, the index of inequality is given by the sum (weighted by the uncertainty) of the co-payment prices. From a methodological perspective, we use the Hierarchy Stochastic Multiobjective Acceptability Analysis. This new modification of the standard SMAA allows 
dealing with Multi-Criteria Decision Making problems with a hierarchical structure, as in the case of the Italian health care co-payment system. In our case, HSMAA measures the inequality, allowing us to create a unique index for each region and then rank them. Indeed, by aggregating the data of prices of public health care services with HSMAA, we estimate a new index of inequality of opportunities in public health care.

Our results show that, under the 'veil of ignorance' about health needs, the Campania (a Southern region) is by far the worst region. On the contrary, we found that Friuli Venezia Giulia (a Northern region) has the cheapest public health care. These evidences make clear that Italy, with these circumstances, will never have a convergence path, either in economic performances in well-being or in civil rights. Indeed, the price of access to public health changes within the country, region by region. This paradox causes a territorial inequality of access in the same country, even if there is a National Public Health System. Such difference has been described as a 'postcode lottery' that contributes to social and spatial disparities, because people's access to public services is determined by the postcode area in which they live [60]. These differences should not exist, since the Italian Constitution provides the right for the Essential Levels of Care in equal measure on all national territories.

As further research, this paper proves that many problems related to the public sector can be studied with the Multi-Criteria Decision Making approach. More generally, public economics science needs tools to manage the multidimensionality of the phenomena in a holistic approach. For instance, the way HSMAA manages the uncertainty can help with deeply understanding the complexity of social phenomena, which are the most relevant components in the market/government relationship path. Policymakers dealing with collective choices need tools to manage the multidimensionality of phenomena and the heterogeneity of individual preferences. A plurality of individuals with different preferences can be replaced by means of a plurality of vectors of weights. The HSMAA approach explicitly takes into account this issue, considering the whole space of feasible weight vectors. This feature makes HSMAA a valid support for better-informed decision and policy formulation.

\section{References}

\section{References}

[1] Allin, S., Masseria, C., Sorenson, C., Papanicola, I., \& Mossialos, E. Measuring inequalities in access to health care. A review of the indices. European Commission 2010, Brussels, Belgium.

[2] Angilella, S., Bottero, M., Corrente, S., Ferretti, V., Greco, S., \& Lami, I. M. Non Additive Robust Ordinal Regression for urban and territorial planning: an application for siting an urban waste landfill. Annals of Operations Research 2016b, 245(1-2), 427-456.

[3] Angilella, S., Corrente, S., \& Greco, S. Stochastic multiobjective acceptability analysis for the Choquet integral preference model and the scale construction problem. European Journal of Operational Research 2015, 240(1), 172-182. 
[4] Angilella, S., Corrente, S., Greco, S., \& Słowiński, R. Robust Ordinal Regression and Stochastic Multiobjective Acceptability Analysis in multiple criteria hierarchy process for the Choquet integral preference model. Omega 2016a, 63, 154-169.

[5] Baltagi B. H., Lagravinese R., Moscone F., \& Tosetti E. Health Care Expenditure and Income: A Global Perspective. Health Economics 2016.

[6] Berk M. and Schur C. Measuring Access To Care: Improving Information For Policymakers. Health Affairs 1998; 17(1), 180.

[7] Braveman P. and Gruskin S. Defining Equity in Health. Journal of Epidemiology and Community Health 2003; 57(4), 254-258.

[8] Bruno, G., \& Genovese, A. Location analysis for public sector decision-making in uncertain times: An introduction to the special issue. Socio-Economic Planning Sciences 2016; (53), 2-3.

[9] Buchanan J. The inconsistencies of the National Health Service. Istitute of Economics Affairs 1965, London.

[10] Burkey, M. L., Bhadury, J., \& Eiselt, H. A. A location-based comparison of health care services in four US states with efficiency and equity. Socio-Economic Planning Sciences 2012; 46(2), 157-163.

[11] Charnes, A., Cooper, W. W., \& Rhodes, E. Measuring the efficiency of decision making units. European Journal of Operational Research 1978, 2(6), 429-444.

[12] Corrente, S., Figueira, J. R., \& Greco, S. The smaa-promethee method. European Journal of Operational Research 2014, 239(2), 514-522.

[13] Corrente, S., Figueira, J. R., Greco, S., \& Słowiński, R. A robust ranking method extending ELECTRE III to hierarchy of interacting criteria, imprecise weights and stochastic analysis. Omega 2017, 73, 1-17

[14] Corrente, S., Greco, S., \& SłOwińSki, R. Multiple criteria hierarchy process in robust ordinal regression. Decision Support Systems 2012, 53(3), 660-674.

[15] Culyer A.J., van Doorsalaer E. and Wagstaff A. Access, utilisation and equity: a further comment. Journal Health Economics 1992, 207-210.

[16] Culyer A.J. and Wagstaff A. Equity and equality in health and health care. Journal of Health Economics 1993; 12(4), 431-457.

[17] de Belvis A.G., Ferrè F., Specchia M.L., Valerio L., Fattore G., Ricciardi W. The financial crisis in Italy: Implications for the health care sector. Health Policy 2012, 106, 10-16. 
[18] Dirindin N. Un ticket che porta alla sanità privata. lavoce.info 2011.

[19] Emrouznejad, A., Banker, R., Lopes, A. L. M., \& de Almeida, M. R. Data envelopment analysis in the public sector. Socio-economic planning sciences 2014; 1(48), 2-3.

[20] Fleurbaey M., Schokkaert E. Equity in health and health care. CORE Discussion Paper (2011/26) 2011.

[21] Giannoni M. and Franzini L. Determinants of health disparities between Italian regions. BMC Public Health 2010, 10:296.

[22] Giannoni M. and Masseria C. Equity in access to health care in Italy: a disease-based approach. European Journal of Public Health 2010.

[23] Gouveia M. Majority rule and the public provision of a private good. Public Choice 1997; 93(3-4), 221-244.

[24] Greco S., Figueira J., \&Ehrgott M. Multiple criteria decision analysis. Springer's International series 2005.

[25] Greco S., Ishizaka A., Matarazzo B., \& Torrisi G. Stochastic Multiattribute Acceptability Analysis: an application to the ranking of Italian regions. Regional Studies 2017; 1-16.

[26] Gulliford, M., Figueroa-Munoz, J., Morgan, M., Hughes, D., Gibson, B., Beech, R., \& Hudson, M. What does 'access to health care' mean? Journal of health services research \& policy 2002; 7(3), 186188.

[27] Healy J., McKee M. Accessing health care: responding to diversity. Oxford University Press 2004.

[28] ISTAT. EU-SILC (Statistics on Income and Living Conditions) 2016, Rome.

[29] Kakwani, N. C. Measurement of tax progressivity: an international comparison. The Economic Journal 1977; 87.345, 71-80.

[30] Klomp, J., de Haan, J. Measuring health: a multivariate approach. Social indicators research 2010, 96(3), 433-457.

[31] Koc C. Disease-specific moral hazard and optimal health insurance design for physician services. The journal of risk and insurance 2011; 78(2), 413-446

[32] Ishizaka A., \&Nemery P. Multi-criteria decision analysis: methods and software. John Wiley $\mathcal{E}$ Sons 2013.

[33] Jana, A., \& Harata, N. Provisioning health care infrastructure in communities: Empirical evidences from West Bengal, India. Socio-Economic Planning Sciences 2016; 54, 2016. 37-46.

[34] Joumard I., André C., \& Nicq C. Health care systems: efficiency and institutions. OECD 2010; Paris. 
[35] Lahdelma R., Hokkanen J., \& Salminen P. SMAA-stochastic multiobjective acceptability analysis. European Journal of Operational Research 1998; 106(1), 137-143.

[36] Lahdelma, R., Miettinen, K., \& Salminen, P. Ordinal criteria in stochastic multicriteria acceptability analysis (SMAA). European Journal of Operational Research 2003, 147(1), 117-127.

[37] Lahdelma R., \&Salminen P. SMAA-2: Stochastic multicriteria acceptability analysis for group decision making. Operations Research 2001; 49(3), 444-454.

[38] Lahdelma, R., \& Salminen, P. Stochastic multicriteria acceptability analysis using the data envelopment model. European Journal of Operational Research 2006, 170(1), 241-252.

[39] Le Grand J. The Strategy of Equality, 1982 London.

[40] Lindeboom M., van Doorslaer E. Cut-Point Shift and Index Shift in Self-Reported Health. Journal of Health Economics 2004; 23(6), 1083-1099.

[41] Mahdavi, M., Malmström, T., van de Klundert, J., Elkhuizen, S., \& Vissers, J. Generic operational models in health service operations management: a systematic review. Socio-Economic Planning Sciences 2013; 47(4), 271-280.

[42] Monte A. D., \& Luzenberger R. D. The effect of regional policy on new firm formation in Southern Italy. Regional Studies 1989; 23(3), 219-230.

[43] Mooney G. Equity in health care: confronting the confusion. Effective Health Care 1983; 1(4), 179-185.

[44] Morgan M., Gulliford M. Access to health care, 2003; Routledge.

[45] Morris S., Sutton M. and Gravelle H. Inequity and inequality in the use of health care in England: an empirical investigation. The University of York, 2003.

[46] Mossialos E., Oliver A. Equity of access to health care: outlining the foundations for action. Journal Epidemiology and Community Health 2004; 58(8), 655-658.

[47] Muraro G., Rebba V. Caratteri del mercato sanitario e giustificazioni dell'intervento pubblico in sanità. Dipartimento di Scienze Economiche 2010; Padova.

[48] Nuti S. and Segheri C. Is variation management included in regional healthcare governance system? Some proposals from Italy. Health Policy, 2014.

[49] O'Donnell O., van Doorslaer E., Wagstaff A., Lindelow M. Analyzing Health Equity Using Household Survey Data: A guide to techniques and their implementation. The World Bank Institute 2008, Washington, USA.

[50] Palin J., Zumbo D. Measurement of Health Care Utilization in Canada: Agreement between Surveys and Administrative Records. Statistics Canada 2003; Ottawa. 
[51] Patrizii V., \&Resce G. Public Sector Contribution to Competitiveness. Italian Economic Journal 2015; 1(3), 401-443.

[52] Pauly M.V. Taxation, health insurance and market failure in the medical economy. Journal of Economics Literature 1968; 24(2), 629-675

[53] Rawls, J. A Theory of Justice. Cambridge 1971; Mass: Harvard University Press

[54] Redigor E. Measures of health inequalities: part 1. Journal of Epidemiology and Community Health 2004; 58(10), 858.

[55] Roemer J.E., John E. Equality of Opportunity. Cambridge 1998. MA: Harvard University Press.

[56] Saaty, T. L. How to make a decision: the analytic hierarchy process. European Journal of Operational Research 1990, 48(1), 9-26.

[57] Spadavecchia A. Regional and national industrial policies in Italy, 1950s-1993. Where did the subsidies flow?. Economics and management discussion paper 2007; 48.

[58] Taccone A. Efficienza ed equità della compartecipazione degli utenti al finanziamento delle prestazioni sanitarie pubbliche. Dipartimento di Scienze Economiche e Aziendali 2008; LUISS Guido Carli, Roma.

[59] Tervonen, T., \& Lahdelma, R. Implementing stochastic multicriteria acceptability analysis. European Journal of Operational Research 2007, 178(2), 500-513.

[60] Thomas B., \& Dorling D. Identity in Britain: A cradle-to-grave atlas. Policy Press 2007.

[61] Torrisi G., Pike A., Tomaney J., \& Tselios V. (Re-) exploring the link between decentralization and regional disparities in Italy. Regional Studies, Regional Science 2015; 2(1), 123-140.

[62] van Doorslaer E. and Wagstaff A. Equity in the delivery of health care: Some international comparisons. Journal of Health Economics 1992, 389-412.

[63] van Doorslaer E., Masseria C., Koolman X. Inequalities in access to medical care by income in developed countries. OECD Health Equity Research Groups 2006.

[64] Wagstaff, A., Van Doorslaer, E., \& Paci, P. On the Measurement of Horizontal Inequity in the Delivery of Health Care. Journal of Health Economics 1991; 10(2), 169-205.

[65] Wagstaff A. et al. Equity in the Finance of Health Care: Some Further International Comparisons. Journal of Health Economics 1999, 18(3), 263-290.

[66] Wagstaff A., van Doordlaer E. Equity in health care finance and delivery. Handbook of Health Economics 2000; North-Holland.

[67] Waters H. R. Measuring equity in access to health care. Social Science \& Medicine 2000. 
[69] Whitehead M, Evandrou M. et al. As the health divide widens in Sweden and Britain, what's happening to access to care?. British Medical Journal 1997; 315(7114), $1006 .$.

[70] World Bank. World Development Indicators database, Washington D.C 2016.

[71] World Health Organization. Constitution of the WHO 1946. Link: http://www.who.int/governance/eb/who_constitution_en.pdf (Last assessed 18 Oct. 2017).

[72] World Health Organization. Launch of the World Health Report 2013: Research for universal health coverage. Beijing 2013, China. 


\section{Appendice}

Rank acceptability indices

\begin{tabular}{|c|c|c|c|c|c|c|c|c|c|c|c|c|c|c|c|c|c|c|c|c|c|}
\hline Rank & PI & $\mathrm{AO}$ & $\mathrm{LO}$ & $\mathrm{BO}$ & TR & FR & VE & LI & EM & TU & UM & MA & LA & $\mathrm{AB}$ & $\mathrm{MO}$ & CA & $\mathrm{AP}$ & BA & CA & SA & SI \\
\hline 1 & $4 \%$ & $0 \%$ & $7 \%$ & $0 \%$ & $0 \%$ & $0 \%$ & $0 \%$ & $0 \%$ & $0 \%$ & $0 \%$ & $0 \%$ & $0 \%$ & $0 \%$ & $0 \%$ & $0 \%$ & $97 \%$ & & & & & $0 \%$ \\
\hline 2 & $16 \%$ & $0 \%$ & $18 \%$ & $48 \%$ & $0 \%$ & $0 \%$ & $0 \%$ & $0 \%$ & $0 \%$ & $0 \%$ & $0 \%$ & & & & $0 \%$ & & & $0 \%$ & $34 \%$ & $\%$ & $0 \%$ \\
\hline 3 & $24 \%$ & $0 \%$ & $25 \%$ & $9 \%$ & $0 \%$ & $0 \%$ & $1 \%$ & $1 \%$ & & & & & & & & & & $\%$ & $37 \%$ & & $\%$ \\
\hline 4 & $22 \%$ & $0 \%$ & $20 \%$ & $8 \%$ & $0 \%$ & $0 \%$ & $2 \%$ & $2 \%$ & $0 \%$ & $0 \%$ & $0 \%$ & $0 \%$ & $9 \%$ & $0 \%$ & $0 \%$ & $0 \%$ & $10 \%$ & & $9 \%$ & $\%$ & $0 \%$ \\
\hline 5 & $13 \%$ & $0 \%$ & $12 \%$ & $4 \%$ & $0 \%$ & $0 \%$ & $21 \%$ & $21 \%$ & $0 \%$ & $0 \%$ & $0 \%$ & $0 \%$ & $25 \%$ & $0 \%$ & $0 \%$ & $0 \%$ & $14 \%$ & & $3 \%$ & $0 \%$ & $7 \%$ \\
\hline 6 & $6 \%$ & $0 \%$ & $5 \%$ & $2 \%$ & $0 \%$ & $0 \%$ & $28 \%$ & $28 \%$ & $0 \%$ & $1 \%$ & $0 \%$ & $0 \%$ & $18 \%$ & $0 \%$ & $0 \%$ & $0 \%$ & $6 \%$ & $\%$ & $1 \%$ & $2 \%$ & $20 \%$ \\
\hline 7 & $3 \%$ & $0 \%$ & $3 \%$ & $1 \%$ & $0 \%$ & $0 \%$ & $28 \%$ & $28 \%$ & $0 \%$ & $10 \%$ & $0 \%$ & $0 \%$ & $5 \%$ & $0 \%$ & $0 \%$ & & $6 \%$ & & $4 \%$ & $5 \%$ & $15 \%$ \\
\hline 8 & $1 \%$ & $0 \%$ & $1 \%$ & $2 \%$ & $0 \%$ & $0 \%$ & $15 \%$ & $15 \%$ & $0 \%$ & $5 \%$ & $0 \%$ & $0 \%$ & $9 \%$ & $4 \%$ & $0 \%$ & & $2 \%$ & & $\%$ & $2 \%$ & $16 \%$ \\
\hline 9 & $0 \%$ & $0 \%$ & $0 \%$ & $5 \%$ & $0 \%$ & $0 \%$ & $6 \%$ & $6 \%$ & $0 \%$ & $12 \%$ & $0 \%$ & $0 \%$ & $17 \%$ & $1 \%$ & $5 \%$ & $0 \%$ & $5 \%$ & $0 \%$ & $9 \%$ & $5 \%$ & $21 \%$ \\
\hline 10 & $1 \%$ & $0 \%$ & $1 \%$ & $2 \%$ & $0 \%$ & $0 \%$ & & & $4 \%$ & $13 \%$ & & & $6 \%$ & $4 \%$ & $19 \%$ & $\%$ & $19 \%$ & & $\%$ & $17 \%$ & $12 \%$ \\
\hline 11 & $1 \%$ & $0 \%$ & $0 \%$ & $2 \%$ & $0 \%$ & $0 \%$ & $0 \%$ & $0 \%$ & $7 \%$ & $10 \%$ & $7 \%$ & $8 \%$ & $4 \%$ & $1 \%$ & $23 \%$ & $0 \%$ & $18 \%$ & $\%$ & $0 \%$ & $25 \%$ & $5 \%$ \\
\hline 12 & $1 \%$ & $2 \%$ & $1 \%$ & $2 \%$ & $0 \%$ & $4 \%$ & $0 \%$ & $0 \%$ & $3 \%$ & $9 \%$ & $3 \%$ & $37 \%$ & $1 \%$ & $3 \%$ & $23 \%$ & $0 \%$ & $3 \%$ & $0 \%$ & $0 \%$ & $20 \%$ & $0 \%$ \\
\hline 13 & $1 \%$ & $4 \%$ & $0 \%$ & $3 \%$ & $0 \%$ & $3 \%$ & & & $11 \%$ & $39 \%$ & $11 \%$ & $27 \%$ & & $1 \%$ & $14 \%$ & & & & & & $1 \%$ \\
\hline 14 & $3 \%$ & $2 \%$ & $0 \%$ & $2 \%$ & $0 \%$ & $0 \%$ & $0 \%$ & $0 \%$ & $74 \%$ & $0 \%$ & $74 \%$ & $0 \%$ & $2 \%$ & $0 \%$ & $5 \%$ & $0 \%$ & $3 \%$ & $0 \%$ & $0 \%$ & $1 \%$ & $2 \%$ \\
\hline 15 & $0 \%$ & $6 \%$ & $0 \%$ & $0 \%$ & $0 \%$ & $1 \%$ & $0 \%$ & & & & $1 \%$ & $1 \%$ & $1 \%$ & $0 \%$ & $4 \%$ & & & & $\%$ & $\%$ & $0 \%$ \\
\hline 16 & $3 \%$ & $1 \%$ & $4 \%$ & $2 \%$ & $24 \%$ & $5 \%$ & $0 \%$ & & & $0 \%$ & $0 \%$ & $11 \%$ & & $21 \%$ & $2 \%$ & & & & & & $0 \%$ \\
\hline 17 & $0 \%$ & $14 \%$ & $2 \%$ & $4 \%$ & $43 \%$ & $5 \%$ & $0 \%$ & $0 \%$ & $0 \%$ & $0 \%$ & $0 \%$ & $4 \%$ & $1 \%$ & $15 \%$ & $2 \%$ & $0 \%$ & $0 \%$ & $1 \%$ & $0 \%$ & $3 \%$ & $0 \%$ \\
\hline 18 & $0 \%$ & $51 \%$ & $1 \%$ & $2 \%$ & $22 \%$ & $3 \%$ & $0 \%$ & $0 \%$ & $0 \%$ & $0 \%$ & $0 \%$ & $3 \%$ & $0 \%$ & $5 \%$ & $3 \%$ & $0 \%$ & $0 \%$ & $6 \%$ & $0 \%$ & $0 \%$ & $0 \%$ \\
\hline 19 & $0 \%$ & $19 \%$ & $0 \%$ & $1 \%$ & $10 \%$ & $3 \%$ & $0 \%$ & $0 \%$ & $0 \%$ & $0 \%$ & $0 \%$ & $1 \%$ & $0 \%$ & $0 \%$ & $0 \%$ & $0 \%$ & $0 \%$ & $59 \%$ & $0 \%$ & $8 \%$ & $0 \%$ \\
\hline 20 & $0 \%$ & $0 \%$ & $0 \%$ & $1 \%$ & $1 \%$ & $1 \%$ & $0 \%$ & $0 \%$ & $0 \%$ & $0 \%$ & $0 \%$ & $8 \%$ & $0 \%$ & $32 \%$ & $0 \%$ & $0 \%$ & $0 \%$ & $24 \%$ & $0 \%$ & $0 \%$ & $0 \%$ \\
\hline 21 & $0 \%$ & $0 \%$ & $0 \%$ & $0 \%$ & $0 \%$ & $75 \%$ & $0 \%$ & $0 \%$ & $0 \%$ & $0 \%$ & $0 \%$ & $0 \%$ & $0 \%$ & $13 \%$ & $0 \%$ & $0 \%$ & $0 \%$ & $0 \%$ & $0 \%$ & $0 \%$ & $0 \%$ \\
\hline
\end{tabular}

Notes: PI=Piedmont; AO=Aosta Valley; LO=Lombardy; BO=Bozen; TR=Trento; FR=Friuli Venezia Giulia; VE=Veneto; LI=Liguria; EM=Emilia-Romagna; TU=Tuscany; $\mathrm{UM}=\mathrm{Umbria}$;A=Marche; $\mathrm{LA}=\mathrm{Lazio}$; $\mathrm{AB}=\mathrm{Abruzzi} \mathrm{MO}=$ Molise; $\mathrm{CA}=$ Campania; $\mathrm{AP}=\mathrm{Apulia}$; $\mathrm{BA}=\mathrm{Basilicata} \mathrm{CL}=$ Calabria; $\mathrm{SA}=\mathrm{Sardinia}$; $\mathrm{SI}=\mathrm{Sicily}$. 
